
\title{
28 Research Soure \\ Lessons, narratives and research directions for a sustainable circular economy
}

\section{Sina Leipold}

University of Freiburg

Anna Petit-Boix ( $\square$ anna.petit.boix@transition.uni-freiburg.de )

University of Freiburg https://orcid.org/0000-0003-2048-2708

Anran Luo

University of Freiburg

Hanna Helander

University of Freiburg https://orcid.org/0000-0002-6773-3300

Machteld Simoens

University of Freiburg

Weslynne Ashton

Illinois Institute of Technology

Callie Babbitt

Rochester Institute of Technology https://orcid.org/0000-0001-5093-2314

Alba Bala

UNESCO Chair in Life Cycle and Climate Change, ESCI-UPF

Catharina Bening

Swiss Federal Institute of Technology Zurich (ETHZ)

\section{Morten Birkved}

University of Southern Denmark

\section{Fenna Blomsma}

University of Hamburg

\section{Casper Boks}

NTNU Norwegian University of Science and Technology

\section{Alessio Boldrin}

Technical University of Denmark

\section{Pauline Deutz}

University of Hull https://orcid.org/0000-0002-9165-5322

\section{Teresa Domenech}

Bartlett School Environment, Energy \& Resources, University College London (UCL) https://orcid.org/0000-0002-6131-5538

\section{Navarro Ferronato}

University of Insubria 


\section{Alejandro Gallego-Schmid}

University of Manchester https://orcid.org/0000-0002-0583-2143

\section{Damien Giurco}

University of Technology Sydney https://orcid.org/0000-0002-1707-9531

\section{Kersty Hobson}

Cardiff University

\section{Roope Husgafvel}

Aalto University https://orcid.org/0000-0001-8502-1131

Cynthia Isenhour

University of Maine

\section{Mait Kriipsalu}

Estonian University of Life Sciences

\section{Donato Masi}

Aston University

Joan Manuel F Mendoza

Ikerbasque, Basque Foundation for Science \& Mondragon Unibertsitatea

\section{Leonidas Milios}

Lund University

\section{Monia Niero}

Aalborg University

\section{Deepak Pant}

Flemish Institute for Technological Research (VITO) https://orcid.org/0000-0002-1425-9588

\section{Keshav Parajuly}

United Nations University \& University of Limerick

\section{Stefan Pauliuk}

University of Freiburg https://orcid.org/0000-0002-6869-1405

\section{Marina Pieroni}

Technical University of Denmark

\section{Jessika Richter}

Lund University

\section{Michael Saidani}

University of Illinois at Urbana-Champaign https://orcid.org/0000-0002-8269-4477

\section{Marzena Smol}

Polish Academy of Sciences

\section{Laura Talens Peiró}

Universitat Autònoma de Barcelona

\section{Stijn Van Ewijk}

Yale University https://orcid.org/0000-0002-8894-4692

\section{Walter Vermeulen}


Utrecht University

Dominik Wiedenhofer

University of Natural Resources and Life Sciences, Vienna (BOKU) https://orcid.org/0000-0001-74183477

\section{Bing Xue}

Institute for Advanced Sustainability Studies https://orcid.org/0000-0002-7790-1216

\section{Article}

Keywords: circular economy, sustainability, narratives, policy relevance, research impact, ambiguity

Posted Date: July 2nd, 2021

DOI: https://doi.org/10.21203/rs.3.rs-429660/v1

License: (c) (1) This work is licensed under a Creative Commons Attribution 4.0 International License. Read Full License

Version of Record: A version of this preprint was published at Journal of Industrial Ecology on December 27th, 2022. See the published version at https://doi.org/10.1111/jiec.13346. 


\section{Abstract}

The current enthusiasm for circular economy (CE) offers a unique opportunity to advance the impact of research on sustainability transitions. Diverse interpretations of CE by scholars, however, produce partly opposing assessments of its potential benefits, which can hinder progress. Here, we synthesize policyrelevant lessons and research directions for a sustainable CE and identify three narratives - optimist, reformist and skeptical - that underpin the ambiguity in CE assessments. Based on 54 key CE scholars' insights, we identify three research needs: the articulation and discussion of ontologically distinct CE narratives; bridging of technical, managerial, socio-economic, environmental and political CE perspectives; and critical assessment of opportunities and limits of CE science-policy interactions. Our findings offer practical guidance for scholars to engage reflexively with the rapid expansion of $C E$ knowledge, identify and pursue high-impact research directions, and communicate more effectively with practitioners and policymakers.

\section{Introduction}

Few other sustainability-related concepts have been able to spark the imagination, enthusiasm and commitment of academics, businesses, non-governmental organizations (NGOs), and governments worldwide as the circular economy (CE). Presenting a distinct perspective on value creation, the CE aims to enhance efficiency and sufficiency of resource use, offering a "toolbox" for innovation towards an environmentally, socially and economically sustainable world ${ }^{1,2}$. Given the CE's transformative aspirations, many research efforts aim to produce policy-relevant knowledge supporting profound changes towards sustainability - which we understand as sustaining human life within a safe and just operating space ${ }^{3}$.

While reviews of existing CE research are abundant ${ }^{4-6}$, few condense policy-relevant knowledge ${ }^{7}$. More importantly, the complexity of the CE concept has produced widely diverging scholarly assessments regarding its technical, socio-economic, environmental, and regulatory potential and challenges ${ }^{8}$. While many CE accounts are celebratory 9,10 , fundamental criticism on the CE's core assumptions ${ }^{11}$, social benefits $^{12}$ and contribution to environmental sustainability is rising ${ }^{13,14}$. In addition, comprehensive accounts of future directions for $\mathrm{CE}$ research are lacking. Research agendas and frameworks remain fragmented and focused on particular aspects. These include industrial activities ${ }^{15,16}$, business models $^{17,18}$, communication ${ }^{19}$, systematic monitoring ${ }^{20,21}$, and governance ${ }^{7,22}$. This study argues that the CE's ambiguity, i.e. allowing for several interpretations, contributes to these diverging assessments and lack of shared direction. Such ambiguity is a common feature of broad concepts like $\mathrm{CE}^{23}$.

If academics are to provide policy-relevant evidence on the potential benefits of $C E$, such ambiguity is both a challenge and an opportunity. Research on science-policy interaction has shown extensively that it can be a challenge to inform policy and practice, as evidence does not provide straightforward courses of action $^{24}$. At the same time, this lack of conclusiveness can be an opportunity for "issue entrepreneurs", 
who promote a new issue in a policy field, to pursue political decision-making that supports particular, individual or group preferences ${ }^{25}$.

To aid scholarly engagement with the potentials and pitfalls of diverging assessments, this study brings together 1) policy-relevant lessons and 2) research questions on a sustainable $C E$, that are key for the $C E$ research community. The article further outlines narratives underlying the lessons and questions, which highlight different scholarly CE interpretations. The results are based on a survey of lessons and questions on how to achieve a "sustainable CE", which did not pre-define CE and sustainability. Fifty-four key international CE scholars participated, having diverse (inter)disciplinary backgrounds, subsequent ontologies, and experiences working towards transformational knowledge and action for sustainability. To condense lessons, map repeating scholarly CE interpretations and develop a shared research agenda, a core research team summarized and grouped the lessons while the survey participants ranked and discussed the questions in a process inspired by Delphi methods (Fig. 1, also see methods section).

The results present the first systematic examination of policy-relevant knowledge for a sustainable $\mathrm{CE}$, with new insights not covered in traditional literature reviews. The research agenda offers a unique group opinion across different CE interpretations. Based on these novel insights, this study proposes three avenues to aid scholarly dialogue on the potentials and pitfalls of the CE's ambiguity to (1) support informed conclusions on available knowledge and (2) reflexively engage with calls for policy-relevant CE research.

\section{Narratives Of Policy-relevant Lessons For A Sustainable Ce}

The 54 survey participant's insights highlight lines of convergence and divergence about policy-relevant lessons for a sustainable CE. These synthesize three ideal typical narratives: optimist, reformist and skeptical (Fig. 2, detailed lessons in Supporting Information 1). This article uses narratives to structure the lessons because scholars habitually narrate to reduce complexity and connect the past, present and future, particularly when making sense of complex, future-oriented chang $\mathrm{e}^{26}$. A narrative is a story that ascribes meaning to social or physical phenomena and provides an interpretation of who or what is significant ${ }^{27}$. The optimist, reformist and skeptical CE narratives hold different ontological viewpoints, determining what is real in the world and what is relevant for a sustainable CE. These narratives provide novel insights into convergence and divergence of scholarly views on policy-relevance and societal change, complementing results on scholarly CE narratives developed based on scientific literature ${ }^{28}$.

First, the optimist narrative takes $C E$ as a fundamental part of sustainability transformations and suggests specific actions to reach a sustainable CE. Second, the reformist narrative argues that the CE has transformative potential but only if social and environmental boundary conditions are met. This narrative anticipates that good policy (design and implementation) could use the CE concept to ignite and advance a sustainability transformation, if status quo interests are overcome and potential rebound effects or burden shifts are addressed. Finally, the skeptical narrative questions the general usefulness of a CE for sustainability transformations. Based on the perception that CE is an empty concept that is 
unreflective of the consequences of economic growth, this narrative expects that the concept serves business-as-usual practices or may accelerate environmental degradation by fostering economic growth with no (or only relative) decoupling from resource consumption.

The optimist narrative takes CE as a driver for sustainability transformations. Particularly in the political theme, it is noteworthy that the majority of lessons hardly touch on CE objectives but assume that these are implicitly clear and beneficial for a sustainability transformation. This narrative considers CE as the only form of human development within planetary boundaries. Consequently, lessons focus on what is needed to achieve a $\mathrm{CE}$, which is usually resource efficiency policies and business action at the local or national level, e.g. Eco-Design or Extended Producer Responsibility. While some lessons suggest awareness raising to promote $\mathrm{CE}$ behaviors and lifestyles, education policies hardly appear. In the economic dimension, CE is portrayed as a powerful metaphor that breaks silo thinking, engages companies and provides economic benefits. At the same time, many lessons argue that the economy requires more or better steering through policies. Hence, political action plays a much more influential role than economic or technical aspects. Notably, these lessons do not correspond with current EU institutions' CE narrative, which portrays bottom-up market forces and economic incentives as CE drivers $^{28,30,31}$. Despite the optimist narrative's focus on policies, however, many lessons still highlight the need for new business models, data and technology to deploy a sustainable CE.

The reformist narrative connects risks and disadvantages related to the CE to policy. Lessons often anticipate that good policy (design and implementation) could use the CE concept to ignite and advance sustainability transformation. Yet, policies can only do so if they overcome two key problems: the resistance of status quo interests and the growth of resource consumption, emissions and socioeconomic material stocks (infrastructures, buildings and products). In this narrative, political action and consumption-production patterns are more critical for CE development than technological advances. Yet, political, social and economic change needs to foresee and mitigate greenwashing, rebound effects and burden shifting. However, some lessons raise the issue that not enough room for innovation or experimentation exists. Furthermore, the reformist narrative suggests taking measures to expand our knowledge and action on social dimensions of a CE, e.g. consumption habits, ownership, working conditions, lifestyles, as neglecting social dimensions limits a CE's potential from a triple bottom line perspective.

The skeptical narrative questions a CE's usefulness for sustainability transformations. It expects that the concept serves as an excuse for business-as-usual or opens possibilities for accelerated resource consumption by promoting economic growth. Accordingly, economic lessons of this narrative argue that business-led circularity is a myth. Instead, businesses are understood as using the CE concept's vagueness to prevent rather than promote value retention of materials. While this critique is similar to the reformist argument regarding the resistance of status quo interests (e.g. fossil fuel industry) and the danger of greenwashing, the skeptical narrative differs significantly by questioning whether CE policy can overcome status quo resistance or the deep-rooted economic growth paradigm. In the social dimension, this narrative highlights that shifting ownership models, e.g. moving to sharing/rental models, may 
exclude disadvantaged groups in society and these groups will bear the costs of a CE transformation as currently envisioned by the optimist narrative. This neglect of disadvantaged groups will lead to considerable resistance to change. Furthermore, such change would not be a "real" social transformation but rather "managerial-techno-optimism" (Supporting Information 1). Under this narrative, a CE requires a reorientation of the current socio-economic system, e.g. to de-growth or well-being indicators, at which current CE efforts are failing. Therefore, this narrative argues that available evidence only weakly substantiates the environmental or social benefits of current CE implementation efforts.

Across all three narratives, the lessons portray policy interventions as crucial for CE success, although each narrative qualifies them differently. While the optimist narrative argues that CE policies need coordination across governance levels and monitoring, the reformist narrative highlights the need to overcome vested interests, and the skeptical narrative argues for policies addressing fundamental issues of growth and capitalism. Next to the emphasis on political intervention, the lessons in all three narratives highlight the importance of social processes and participation for sustainable CE development, specifically calling for the inclusion of diverse (local) stakeholders. Finally, many lessons call for a "common language" or a shared CE conceptualization and framing as well as an understanding of limitations (e.g. in-use material growth, quality and quantity).

\section{Research Priorities For The Future}

To develop a shared research agenda, the 54 survey participants suggested, ranked and discussed a broad array of research questions critical for policy-relevant CE knowledge (see methods), which mirror the concerns and positions identified in the three narratives. A list of 20 questions, categorized into four thematic groups, resulted from this exercise (Table 1). As the research questions set a broad agenda, each requires further operationalization in socio-economic, geographic, sectorial and political contexts. Nevertheless, the research questions point to four key priorities for the future, in line with the thematic groups stated in Table 1:

1. Consensus-building on what constitutes a sustainable $C E$. This priority area highlights the need to reflect on the overall goals, definitions, boundaries, principles and associated practices of a CE as suggested by Korhonen et al. ${ }^{23}$ and Blomsma and Brennan ${ }^{32}$, among others. It further calls for research linking CE with wider socio-economic frameworks and objectives ${ }^{33}$ and addressing biophysical resource constraints ${ }^{34}$. This area aims to address the implications of CE for ecosystems, human well-being, notions of sufficiency and economic de-growth. Similar calls have been made by other authors such as Hobson and Lynch ${ }^{35}$.

2. Identify and leverage change opportunities. The second priority area asks for policy and practice options to enable a CE. It seeks to identify mechanisms, policy designs and harmonization strategies enabling a CE transformation, as suggested by Fratini et al. ${ }^{22}$ and Milios ${ }^{9}$, while being sensitive to different governance levels, scales and development stages as suggested by Luo et al. ${ }^{36}$ and Domenech and Bahn-Walkowiak ${ }^{37}$ among others. This proposes new lines of research sensitive to 
governance issues as noted by Govindan and Hasanagic ${ }^{38}$ and Leipold ${ }^{39}$ and their complexity and heterogeneity within and across nation-states. Not least, this priority area highlights the need to reflect critically on whether circular strategies should (always) be favored over linear (business-asusual) strategies ${ }^{11,40}$.

\section{Assess the environmental, economic and social costs and benefits of CE strategies and ways to} distribute them. The third priority area focuses on monitoring CE implementation to steer decisionmaking and to minimize trade-offs or rebound effects through appropriate and commonly shared CE indicators, as also highlighted by Helander et al. ${ }^{41}$ and Saidani et al. ${ }^{21}$. Competing but complementary approaches need to be critically assessed and integrated, as some focus on single products, materials and business models, whereas others assess the entire economy and its relation to (global) environmental goals and strategies ${ }^{21,34}$. It also calls for the identification of societal and political strategies that ensure an adequate distribution of costs and benefits in society as suggested by Hobson ${ }^{42}$ and Simoens and Leipold ${ }^{43}$ among others, taking geographical and cultural differences into account ${ }^{44}$.

4. Reflect on the role of science in supporting CE development. This priority area is concerned with research that investigates the role of CE knowledge in political contexts as suggested by Giampietro and Funtowicz ${ }^{45}$ and when questions of negotiation and decision-making power are involved. It suggests exploring the opportunities and limits of science communication and the collaboration of scholars with stakeholders. 
Table 1

Questions for policy-relevant research on a sustainable circular economy. The left column indicates the narrative each question is based on (Op: optimist narrative, Re: reformist narrative, Sk: skeptical narrative). Due to space limitations, this list of final questions does not include sub-questions developed during the Delphi-inspired exercise. These can be found in Supporting Information 2. The final questions and their sub-questions are the result of collaboratively condensing the 78 original questions proposed by the participants (Supporting Information 3). For more details on the process, please see the methods section.

\section{CONCEPTUALIZING A SUSTAINABLE CIRCULAR ECONOMY}

Re. 1 What does the socio-economic system need to look like to support circularity principles and be socially, environmentally and economically sustainable in different regions?

2 How can the circular economy objectives be linked to the different SDGs and other major environmental and social development targets?

Sk. 3 How can circular economy conceptualizations address the challenges posed by economic growth models, such as the physical constraints of resource and ecosystem regeneration?

4 How can we determine whether or not sufficiency is part of the circular economy and how can we define it?

\section{TRANSFORMING TO A SUSTAINABLE CIRCULAR ECONOMY}

Op. 5 What are the potentials and limitations of harmonization of circular economy policies across countries (e.g. within the EU, countries with different development stages)?

6 What harmonization of policies between levels and scales is needed to support circular practices?

7 How can policies be designed and integrated to increase material resource efficiency at every stage of the life cycle of products and services?

Re. 8 How can we transition to an environmentally sustainable circular economy through outcompeting the linear economy in a given socio-economic system?

9 What mechanisms can ensure that policy and practice support a systemic societal change towards a circular economy?

10 What existing policy options and what new transformative policies enable a sustainable circular economy?

11 How do we leverage a better understanding of the relationship between the formal and informal industrial and service sectors to generate a just transition to a circular economy?

12 How could we move to circular economy business models that are appropriate for countries in different development stages?

Sk. $\quad 13$ Can or should linear economic systems be dis-incentivized and circular systems incentivized, and if so, how?

\section{MONITORING CIRCULAR ECONOMY TO ENSURE SUSTAINABILITY}

Re. 14 What are suitable indicators to measure progress towards circularity and to assess the sustainability of the emerging circular society? 


\section{CONCEPTUALIZING A SUSTAINABLE CIRCULAR ECONOMY}

15 How can we ensure that circular economy initiatives avoid negative effects, including but not limited to, tradeoffs and rebound effects?

16 How can we assess what scale is suitable in order to reach circular economy goals given the characteristics of the specific product systems?

17 What tradeoffs does the implementation of circular systems generate in different geographic and organizational scales?

18 How do we allocate social, environmental and economic costs in circular supply chains from extraction through design, manufacture, retail, use and disposal to recycling?

\section{SCIENCE-POLICY INTERFACE FOR A SUSTAINABLE CIRCULAR ECONOMY}

Re. 19 What are the different pathways in the science-policy interface that make circular economy knowledge taken up by decision-makers?

20 How can life-cycle oriented sustainability assessment be translated into policy in a circular economy context, given that no supply chain is under the control of a single government or a single sector?

As this agenda emerged from a Delphi-inspired process, which aims at determining a group opinion, some important research areas that did not receive enough votes were left out of the final questions (see methods). However, participants pointed them out in their feedback and the core research team identified these topics to be commonly addressed in CE literature. These include the demand side of the $\mathrm{CE}$, especially the role of civil society (e.g. NGOs) and consumer acceptance of circular offerings and adoption of circular lifestyles. These were included in the original list of research questions suggested by the study participants (see Supporting Information 2 and methods) and some of the final questions do use terms such as 'incentivize' or 'engage', which may implicitly address consumers. However, most of the final questions are oriented towards political and supply-side measures. Such questions have also been highlighted by previous work, e.g. Ghisellini et al. ${ }^{4}$ or Lieder and Rashid ${ }^{5}$. Furthermore, research on strategies aimed at slowing resource loops (e.g. sharing economy, collaborative consumption, remanufacturing, reuse, eco-design, second-hand, product-service-system) as well as research on individual enterprises, innovation and the role of technology in achieving CE goals, require more detailed attention. Although these aspects were not ranked among the most pressing research questions, they feature in the lessons (see Supporting Information 1) and have been subject to previous agenda-setting exercises. For instance, Camacho-Otero et al. ${ }^{46}$ explore consumer engagement in a CE from a social perspective and among others Jabbour et al. ${ }^{47}$ call for more engagement with managerial practices and (new) digital technologies in circular supply chains.

Another underrepresented research area that crosscuts the former two are behavioral aspects. Some research addresses issues of sustainable behavior specifically in a CE context ${ }^{48}$ and thereby touches upon the role of the user's responsibility. Researchers argue that some consumer segments would respond to mere information provision, whereas others will need compelling design or force to behave 
according to circular principles. To understand how individuals and enterprises behave when faced with certain regulations, economic incentives or innovations, existing studies call for more research on environmental management systems and the diffusion of circular criteria and requirements in existing processes and eco-labels ${ }^{49}$. Related to these topics, the agenda (Table 1) does not include explicit questions on international agreements and global trade for a $\mathrm{CE}$, which recently emerged in research ${ }^{36}$.

Finally, the agenda does not include explicit questions on (shared) terminology or theoretical frameworks, despite the prominent role given to conceptualizing a sustainable CE. The use and meaning of different terminologies were, however, a recurrent issue in the discussions about research question formulations among the different researchers. Therefore, all research questions were formulated broadly, as their operationalization depends on disciplinary methods and conceptualizations. The absence of shared CE terms and theoretical frameworks can partly be explained by the multiple disciplines involved. In addition, conceptual and terminological ambiguity makes CE attractive and inspiring to diverse researchers ${ }^{32}$.

The proposed research agenda is, to our knowledge, the most comprehensive so far. It covers all areas of a CE instead of specific approaches, sectors, technologies or regions. While some of the suggestions are not novel as standalone issues, viewing them together provides a comprehensive overview of major uncertainties and points of contestation in the CE research landscape. Thus, it provides a first overview of research concerns based on different CE narratives. This comprehensive view will play an important role in facilitating the development of socially relevant research, and incorporate various visions, understandings and legitimizations into scientific endeavors.

\section{Discussion}

The prevailing enthusiasm surrounding CE offers a unique opportunity to advance the impact of research on sustainability transformations. The inclusion of life cycle and business perspectives alongside questions of social inequality, policy harmonization and global trade in the CE community's lessons learned and research agenda highlights the $\mathrm{CE}$ as a unique orienting point to address the interdependency of these concerns. At the same time, this complexity produces ambiguity - which some scholars view as an obstacle to the creation of policy-relevant CE knowledge. To help scholars navigate and communicate $\mathrm{CE}$ knowledge, this analysis suggests three avenues for $\mathrm{CE}$ researchers to better comprehend and manage the challenges and opportunities arising from this ambiguity.

First, this study suggests a deeper reflection on the problem description and narrative underpinning CE studies and comparing it to results from within and beyond CE research. Researchers habitually discuss the quality of their data and analyses. While this is vital to science, potentially transformative $C E$ knowledge can only emerge if scholars critically reflect on the narratives they adhere to as individuals and as a community. Existing CE literature has attributed ambiguous and contradictory results and conclusions to a strong focus on concepts and too little assessment of real-world processes ${ }^{31,40}$, diverging conceptual foundations ${ }^{28}$, and a misinterpretation of core concepts ${ }^{11}$. While these are important explanations, our analysis points to underlying CE narratives as an important factor driving the 
ambiguity of assessments. CE narratives do not just produce different insights on the same phenomenon from different perspectives or scales. They determine the choice of subject, data, and research questions, as well as the policy recommendations scholars (can) make. The optimist narrative, for instance, bears the risk of finding success stories of new policies or business models (e.g. increasing the recycling of materials) without proving that these actions contribute towards the desired socio-environmental sustainability. At the same time, an overly strong focus on the overhaul of the economic or societal system (skeptical narrative) risks overlooking innovations contributing to new economic thoughts and practices. Finally, the reformist narrative's focus on the 'right' means to realize a CE and the mitigation of negative effects may push necessary debates about a CE's desired ends and goals into the background, thus contributing to an increase in diverging CE interpretations. Reflecting on such limitations of specific ontologies will transform ambiguity into an opportunity to support informed conclusions on the range of available knowledge. For instance, it could enable joint studies of optimist, reformist and skeptical viewpoints at the same scale and topic, e.g. specific business models. Such engagement would necessitate comprehension of each other's underlying assumptions about how the world works as well as the need to bring in longstanding debates and knowledge on related topics, e.g. climate, energy or biodiversity - which may eventually be most transformative in the sense of drawing a comprehensive picture of a sustainable CE. The results of this endeavor could enable or outbalance issue entrepreneurship, i.e. actors actively promoting new or previously ignored issues in a policy field, and politically strategic decision-making biased against CE's socio-ecological goals.

\section{Second, scholars need to link technical, environmental and managerial CE research with studies on social costs and benefits, socio-economic disparities and interdependencies as well as connected questions of policy design and harmonization. The research agenda indicates that, if scholars aim for 'systemic', 'holistic' or 'cross-sectoral' CE thinking, such interdisciplinary links are critical. To do so, researchers could draw upon a multitude of methods that sustainability scientists have developed for reflexive, collaborative, inter- and transdisciplinary research ${ }^{50}$. Recent tools were developed, for instance, to reflect on research stances ${ }^{51}$, develop action-oriented knowledge for sustainability and enhance social learning across technical, managerial, social and political perspectives ${ }^{52}$.}

Third, exploring the opportunities and limits of science communication and the intricacies of sciencepolicy interaction is pivotal if $\mathrm{CE}$ research aspires to be policy-relevant and transformative. Disclosing narratives and the underlying ontologies of $\mathrm{CE}$ research, along with public consultation, would be a first step. This could be realized by integrating the wealth of literature on knowledge co-production ${ }^{53}$ and on the role of science in past processes of social change and transformation ${ }^{52}$ in CE thinking. Such engagement would foster a less biased engagement with stakeholders and help close the knowledge gap on the role of science in CE development.

Engagement with underlying narratives, technical, managerial, social, environmental and political $\mathrm{CE}$ perspectives and science-policy interactions is a challenging task for research departments largely organized along disciplinary lines, constrained by short-term funding and pressured to produce 
immediate scientific output. Yet, such an endeavor is an important and necessary task if CE research strives to contribute advice to policy and practice that meets pressing sustainability challenges. Although these issues are not unique to $\mathrm{CE}$ research, the current growth of focus on CE offers particularly strong reasons to spearhead discussions to address them.

\section{Methods}

To identify current policy-relevant lessons on a sustainable CE and propose a research agenda, the core research team (as specified in the authors' contributions) conducted an expert survey with 54 key CE academics in a Delphi-inspired process for creating a research agenda together with survey participants ${ }^{54}$. This process took place online between April and October 2020 and involved a series of methodological steps, which are defined in the following sections. Expert anonymity was ensured in steps 2, 3 and 4, whereas participants interacted in step 5, which included group discussions enabling a unified definition of the research agenda. This Delphi-inspired process is well suited to identify and prioritize problems and actions by enabling expert-based brainstorming, thus consolidating and evaluating a particular problem or question ${ }^{55-57}$. Expert-based brainstorming and discussion formats have also been applied successfully to develop comprehensive, policy-relevant research agendas ${ }^{58,59}$.

\section{Step 1: Identification and selection of experts}

The study relies on experts who have a deep understanding of the topic under analysis, instead of statistical representation ${ }^{56}$. As suggested by the Delphi method, a Knowledge Resource Nomination Worksheet (KRNW) was used to find, identify and finally select these CE academic experts. Three main criteria were used: 1) publication in relevant scientific peer-reviewed journals, 2) expertise and 3) coverage of disciplines in the social and natural sciences and engineering.

The core research team consulted the most recent bibliometric results reported by Geissdoerfer et al. ${ }^{6}$, Merli et al. ${ }^{60}$ and Prieto-Sandoval et al. ${ }^{61}$ to identify the main journals publishing CE research. The experts are authors of articles published in 13 different journals. To generate the first list of authors, a search was conducted on Web of Science to find articles published in each journal, including the term "circular economy" in the title, abstract and/or keywords. As of April 9, 2020, 1481 articles were found, $75 \%$ of which were published in the Journal of Cleaner Production; Resources, Conservation and Recycling; Sustainability, and Waste Management. Additionally, this list was complemented with highimpact articles that might not have been published in these 13 journals. On Web of Science, articles tagged as "highly cited in the field" and "hot papers in the field" were selected. Using the search string "circular economy", 117 articles were found.

After finding the authors, their CE expertise was assessed. This was done by identifying authors with at least 3 publications, which was indicative of an extensive dedication to this research topic. 266 authors complied with this criterion. However, the use of "circular economy" in an article is not always indicative of research conducive to policy-relevant findings. For instance, some authors showed a stronger focus on 
experimental research to test new materials or components at the lab scale or to optimize engineering processes. Although equally relevant for a $\mathrm{CE}$, technical profiles with less emphasis on political and societal processes were excluded. To do so, publications and author profiles were reviewed individually and 83 of them were excluded.

Finally, the disciplinary background of the authors was reviewed to ensure the coverage of social and natural sciences and engineering disciplines. Given the predominance of natural science and engineering, additional authors were searched. Members of exemplary third-party funded CE projects with an interdisciplinary approach were included. Experts from underrepresented disciplines, such as anthropology, were found through CE seminars and events. This process added 11 researchers to the pool of experts.

On May 14, 2020, 179 invitations were sent out via email after removing some authors whose contact details were not available. Invitations included a detailed calendar with the different steps of the research where expert involvement was expected/encouraged and directed the recipients to the survey and later to the subsequent rounds of brainstorming and review.

The survey secured the extensive input of 54 experts. While the recommended size of a Delphi panel is 10 to 18 experts ${ }^{56}$, we took advantage of the study's virtual format to extend the discussion to a larger group of experts and, thus, make it more comprehensive. Certainly, the study does not cover all possible scholarly viewpoints and the participants' background unavoidably influenced the results. Nevertheless, the general topics that emerged would likely surface if this process was replicated with a similarly large and diverse group of participants.

\section{Step 2: Collecting learnings and research questions}

Upon receipt of the invitation, experts were asked to fill out an online survey by June 5, 2020 (see Supporting Information 4). The questions were divided into two blocks. The first block aimed to collect background information, including the main research focus (i.e. disciplinary, interdisciplinary or transdisciplinary), the main disciplines, the focus areas of the expert's CE research in the past 5 years and the number of years they had been integrating this concept into their research. The second block asked two open-ended questions:

1) "Based on your research on the circular economy, what are the three most important policy-relevant learnings that facilitate or hinder a socially just and environmentally sustainable transition?" Three scales (local, national and international) were suggested to structure the relevance of the findings.

2) "In your opinion, what are the three most important questions that should guide future policy-relevant research on the circular economy?"

The 54 experts who filled out the survey were invited to consult with their colleagues and asked to report the number of people they discussed with. As a result, 18 collaborators were consulted. Supporting Information 4 summarizes the participants' disciplinary profiles and research focus. Interdisciplinary 
research is the dominant profile, with a strong interaction between environmental science, engineering and social science. The main areas of research include waste, material recycling, resource efficiency, business models and CE conceptualization.

\section{Step 3: Analyzing the learnings}

The core research team qualitatively coded the pool of policy-relevant lessons following an interpretive approach $^{62,63}$. One member of the core research team was responsible for identifying and condensing the lessons formulated by the participants in their answers. Some were excluded because they were not formulated as lessons or were not clear enough. The first list of lessons was discussed within the core research team. A different member of the core research team conducted a second coding round to review the initial text and propose grouping categories. The core research team reviewed the new list and defined a set of categories, thus achieving intersubjective plausibility ${ }^{64}$.

Since the lessons diverged largely in terms of their stance towards a $\mathrm{CE}$, they were grouped into three narratives, i.e. more critical towards CE and its potential for change (skeptical narrative), more cautiously optimistic (reformist narrative) or very optimistic (optimist narrative). Using these three narratives, the lessons were further split into the political, social, economic, environmental and research dimensions involved in CE research (see Supporting Information 1).

Each lesson was then assigned to each narrative and dimension. To identify overlaps and shorten the formulations, they were split among the core research team and discussed in a final round to ensure an agreed interpretation. The core research team condensed the lessons and gave structure to the narratives of each position. The experts were then invited to provide feedback on the final summary document. The core research team implemented changes on the formulations accordingly. Additional content suggested by the participants was not integrated into the final list in order not to jeopardize the validity of the methodological process.

\section{Step 4: Grouping and prioritizing research questions}

The survey generated 124 explicit research questions and several normative statements. In order to reduce the interpretive bias, normative statements were excluded from the analysis. Most of the questions were not altered. However, a few showed similarities and the core research team grouped them into a single question. This grouping reduced the final list to 78 questions (see Supporting Information 4). Given the wide range of topics and questions collected, the next step was to select a reduced number of research questions in order to define priorities for future policy-relevant and high-impact research. On June 22, 2020, the experts who had previously completed the survey were asked to select 10 questions. To ensure transparency and an agreed understanding with the experts, the regrouped questions were listed in an appendix. Experts were also asked to identify overlapping or similar questions and to provide feedback on the formulations.

The core research team initially created categories to structure the list of questions. However, reaching a consensus was not possible, as various formulations were not clear. The questions were not further 
grouped into categories because this might have generated a selection bias among the participants influenced by a subjective grouping.

41 experts participated in this round. The votes cast for each question were accounted for to create a ranking. The top 20 questions, which received at least 8 votes each, obtained $52 \%$ of the total votes and were thus prioritized for further discussion. However, the experts provided divergent views around the similarities and overlaps among the initial 78 questions. The questions considered to be similar to one or more of the top 20 questions were listed alongside their counterparts to help refine the final list in the group discussions.

\section{Step 5: Refining research questions}

On July 13 and 15, 2020, four discussion sessions with the experts were organized (two sessions per day, 1 hour each). The aim was to formulate research questions that could be operationalized in academic research and that are understandable to experts from different disciplines. Discussions were held in the form of an online video conference. Based on their availability, experts were randomly split into 8 discussion groups (two groups per session). Each group was contacted in advance and provided with a list of 2-3 questions from the top 20 to be discussed during the session. The questions were paired/grouped according to the similarities indicated in the previous round of feedback. 30 experts and the core research team participated in the discussions.

Each 1-hour session had the same structure. Participants introduced themselves and a moderator from the core research team explained the goal of the session. The rules were clarified: 1) questions needing clarification could be reformulated as needed, 2) if they included a mix of concepts or were too long, participants were allowed to formulate a general research question and a maximum of 3 sub-questions, and 3) if the questions to be discussed showed overlaps, they could be combined. Depending on attendance, each group consisted of up to 5 experts, a moderator and a note-taker, who also took an active role in the redefinition of questions. All participants were able to follow the discussion using a shared document where all changes, comments and suggestions were documented. In some instances, moderators referred to the questions listed as similar in the ranking step to identify supporting concepts. When participants did not finalize their set of questions by the end of a session, the core research team consulted their notes and sent a suggested formulation to the group. Participants either approved or provided feedback on the new question.

Once all questions had been discussed, the core research team reviewed the new list to identify overlaps and potential categories. The final list of agreed-upon questions (Table 2) and sub-questions (Supporting Information 2) was shared with all participants to receive written feedback about the categories and formulations. Finally, the core research team implemented changes on the formulations. Similar to the lessons (Step 3), comments referring to missing content were not integrated into the final list in order not to alter the validity of the methodological process.

\section{Limitations}


This study has some limitations in the interpretation and development of the three narratives and the elaboration of the research agenda. Only academic experts were included, as the results are meant to characterize current scientific efforts and lessons to further inform future research. Further, this analysis addresses policy-relevant research for a sustainable CE in general, leaving room for adapting this knowledge to specific geographical scales or socio-economic sectors. Research agendas targeting certain sectors (e.g. food waste management) will benefit from integrating knowledge and experiences from stakeholders, including practitioners, policymakers and civil society.

Given the online configuration of this analysis, which was due to COVID-19 restrictions as well as the invitation of a broad set of international experts, the number and duration of the live discussion rounds was limited. To mitigate this limitation, several rounds of written feedback were undertaken to enable extensive feedback on the final list of research questions and the grouping of lessons into narratives. However, longer, in-person workshops would have enabled a more in-depth discussion of the results, allowing and ensuring that all participants provided input to fill in existing gaps. For this reason, some dimensions are less prominent in our results, as they were not mentioned in the initial survey. Speculative reasons for why certain areas were less addressed could be 'group-think' dynamics during discussion rounds, bias, that participants did not think they relate to policy or simply that they do not conduct research on the topic. To account for this limitation, feedback on observations and statements resulting from the survey was integrated in the results and discussion sections of the manuscript but not in the raw data in order not to alter the original lessons formulated by the experts.

\section{Declarations}

\section{Author Contributions \& Acknowledgements}

DPBR

\section{References}

1. Lazarevic, D. \& Valve, H. Narrating expectations for the circular economy: Towards a common and contested European transition. Energy Res. Soc. Sci. (2017). doi:10.1016/j.erss.2017.05.006

2. Winans, K., Kendall, A. \& Deng, H. The history and current applications of the circular economy concept. Renew. Sustain. Energy Rev. 68, 825-833 (2017).

3. Raworth, K. A Doughnut for the Anthropocene: humanity's compass in the 21st century. Lancet Planet. Heal. 1, 48-49 (2017).

4. Ghisellini, P., Cialani, C. \& Ulgiati, S. A review on circular economy: The expected transition to a balanced interplay of environmental and economic systems. J. Clean. Prod. 114, 11-32 (2016).

5. Lieder, M. \& Rashid, A. Towards circular economy implementation: A comprehensive review in context of manufacturing industry. J. Clean. Prod. 115, 36-51 (2016).

6. Geissdörfer, M., Savaget, P., Brocken, N. \& Hultink, E. J. Circular Economy - a new sustainability paradigm? J. Clean. Prod. 143, 757-768 (2017). 
7. McDowall, W. et al. Circular Economy Policies in China and Europe. J. Ind. Ecol. 21, 651-661 (2017).

8. Singh, S. et al. Thematic exploration of sectoral and cross-cutting challenges to circular economy implementation. Clean Technol. Environ. Policy 23, 915-936 (2021).

9. Milios, L. Advancing to a Circular Economy: three essential ingredients for a comprehensive policy mix. Sustain. Sci. 13, 861-878 (2018).

10. Su, B., Heshmati, A., Geng, Y. \& Yu, X. A review of the circular economy in China: moving from rhetoric to implementation. J. Clean. Prod. 42, 215-227 (2013).

11. Skene, K. R. Circles, spirals, pyramids and cubes: Why the circular economy cannot work. Sustain. Sci. (2018). doi:10.1007/s11625-017-0443-3

12. Millar, N., McLaughlin, E. \& Börger, T. The Circular Economy: Swings and Roundabouts? Ecol. Econ. 158, 11-19 (2019).

13. De Man, R. \& Friege, H. Circular economy: European policy on shaky ground. Waste Manag. Res. 34, 93-95 (2016).

14. Blum, N. U., Haupt, M. \& Bening, C. R. Why 'Circular' doesn't always mean 'Sustainable'. Resour. Conserv. Recycl. 162, 1-3 (2020).

15. Bressanelli, G., Saccani, N., Pigosso, D. C. A. \& Perona, M. Circular Economy in the WEEE industry: a systematic literature review and a research agenda. Sustain. Prod. Consum. 23, 174-188 (2020).

16. Lopes de Sousa Jabbour, A. B., Jabbour, C. J. C., Godinho Filho, M. \& Roubaud, D. Industry 4.0 and the circular economy: a proposed research agenda and original roadmap for sustainable operations. Ann. Oper. Res. 270, 273-286 (2018).

17. Pieroni, M. P. P., McAloone, T. C. \& Pigosso, D. C. A. Business model innovation for circular economy and sustainability: A review of approaches. J. Clean. Prod. 215, 198-216 (2019).

18. Lüdeke-Freund, F., Gold, S. \& Bocken, N. M. P. A Review and Typology of Circular Economy Business Model Patterns. J. Ind. Ecol. 23, 36-61 (2019).

19. Chamberlin, L. \& Boks, C. Marketing Approaches for a Circular Economy: Using Design Frameworks to Interpret Online Communications. Sustainability 10, 2070 (2018).

20. Corona, B., Shen, L., Reike, D., Rosales Carreón, J. \& Worrell, E. Towards sustainable development through the circular economy-A review and critical assessment on current circularity metrics. Resour. Conserv. Recycl. 151, 104498 (2019).

21. Saidani, M., Yannou, B., Leroy, Y., Cluzel, F. \& Kendall, A. A taxonomy of circular economy indicators. J. Clean. Prod. 207, 542-559 (2019).

22. Fratini, C. F., Georg, S. \& Jørgensen, M. S. Exploring circular economy imaginaries in European cities: A research agenda for the governance of urban sustainability transitions. J. Clean. Prod. 228, 974989 (2019).

23. Korhonen, J., Honkasalo, A. \& Seppälä, J. Circular Economy: The Concept and its Limitations. Ecol. Econ. 143, 37-46 (2018). 
24. Cairney, P., Oliver, K. \& Wellstead, A. To Bridge the Divide between Evidence and Policy: Reduce Ambiguity as Much as Uncertainty. Public Adm. Rev. 76, 399-402 (2016).

25. Kingdon, J. W. Agendas, Alternatives, and Public Policies. (1984). doi:10.2307/3323801

26. Grin, J., Rotmans, J. \& Schot, J. Transitions to sustainable development: new directions in the study of long term transformative change. (Routledge, 2010).

27. Hajer, M. The Politics of Environmental Discourse: Ecological Modernisation and the Policy Process. (Clarendon Press, 1995).

28. Calisto Friant, M., Vermeulen, W. J. V \& Salomone, R. A Typology of Circular Economy Discourses: Navigating the Diverse Visions of Contested Paradigm. Resour. Conserv. Recycl. 161, 104917 (2020).

29. Gallego, A., Hospido, A., Moreira, M. T. \& Feijoo, G. Environmental performance of wastewater treatment plants for small populations. Resour. Conserv. Recycl. 52, 931-940 (2008).

30. Zink, T. \& Geyer, R. Circular Economy Rebound. J. Ind. Ecol. 21, 593-602 (2017).

31. Leipold, S. \& Petit-Boix, A. The circular economy and the bio-based sector - Perspectives of European and German stakeholders. J. Clean. Prod. 201, 1125-1137 (2018).

32. Blomsma, F. \& Brennan, G. The Emergence of Circular Economy: A New Framing Around Prolonging Resource Productivity. J. Ind. Ecol. 21, 603-614 (2017).

33. Schroeder, P., Anggraeni, K. \& Weber, U. The Relevance of Circular Economy Practices to the Sustainable Development Goals. J. Ind. Ecol. 23, 77-95 (2019).

34. Haas, W., Krausmann, F., Wiedenhofer, D., Lauk, C. \& Mayer, A. Spaceship earth's odyssey to a circular economy - a century long perspective. Resour. Conserv. Recycl. 163, 105076 (2020).

35. Hobson, K. \& Lynch, N. Diversifying and de-growing the circular economy: Radical social transformation in a resource-scarce world. Futures 82, 15-25 (2016).

36. Luo, A. et al. A New Global Political Force to Address Environmental Change? The Circular Economy Discourse between the EU and China. SocArXiv s8v7e Cent. Open Sci.

37. Domenech, T. \& Bahn-Walkowiak, B. Transition Towards a Resource Efficient Circular Economy in Europe: Policy Lessons From the EU and the Member States. Ecol. Econ. 155, 7-19 (2019).

38. Govindan, K. \& Hasanagic, M. A systematic review on drivers, barriers, and practices towards circular economy: a supply chain perspective. Int. J. Prod. Res. 56, 278-311 (2018).

39. Leipold, S. Transforming ecological modernization 'from within' or perpetuating it? The circular economy as EU environmental policy narrative. Env. Polit. 1-23 (2021). doi:10.1080/09644016.2020.1868863

40. Gregson, N., Crang, M., Fuller, S. \& Holmes, H. Interrogating the circular economy: the moral economy of resource recovery in the EU. Econ. Soc. 44, 218-243 (2015).

41. Helander, H., Petit-Boix, A., Leipold, S. \& Bringezu, S. How to monitor environmental pressures of a circular economy: An assessment of indicators. J. Ind. Ecol. (2019). doi:10.1111/jiec.12924

42. Hobson, K. The limits of the loops: critical environmental politics and the Circular Economy. Env. Polit. 30, 161-179 (2021). 
43. Simoens, M. C. \& Leipold, S. Trading Radical for Incremental Change: The Politics of a Circular Economy Transition in the German Packaging Sector. SocArXiv (2020). doi:doi:10.31235/osf.io/mvx5q

44. Deutz, P. \& Lyons, D. I. Introducing an international perspective on industrial ecology. International Perspectives on Industrial Ecology (2015).

45. Giampietro, M. \& Funtowicz, S. O. From elite folk science to the policy legend of the circular economy. Environ. Sci. Policy 109, 64-72 (2020).

46. Camacho-Otero, J., Boks, C. \& Pettersen, I. Consumption in the Circular Economy: A Literature Review. Sustainability 10, 2758 (2018).

47. Jabbour, C. J. C., Jabbour, A. B. L. de S., Sarkis, J. \& Filho, M. G. Unlocking the circular economy through new business models based on large-scale data: An integrative framework and research agenda. Technol. Forecast. Soc. Change 144, 546-552 (2019).

48. Daae, J., Chamberlin, L. \& Boks, C. Dimensions of Behaviour Change in the context of Designing for a Circular Economy. Des. J. 21, 521-541 (2018).

49. Boyer, R. H. W., Hunka, A. D., Linder, M., Whalen, K. A. \& Habibi, S. Product Labels for the Circular Economy: Are Customers Willing to Pay for Circular? Sustain. Prod. Consum. 27, 61-71 (2021).

50. Keitsch, M. M. \& Vermeulen, W. J. Transdisciplinarity For Sustainability: Aligning Diverse Practices. (Routledge, 2020).

51. Hazard, L., Cerf, M., Lamine, C., Magda, D. \& Steyaert, P. A tool for reflecting on research stances to support sustainability transitions. Nat. Sustain. 3, 89-95 (2020).

52. Caniglia, G. et al. A pluralistic and integrated approach to action-oriented knowledge for sustainability. Nat. Sustain. 4, 93-100 (2021).

53. Norström, A. V. et al. Principles for knowledge co-production in sustainability research. Nat. Sustain. 3, 182-190 (2020).

54. Egfjord, K. F. H. \& Sund, K. J. A modified Delphi method to elicit and compare perceptions of industry trends. Methods X 7, 101081 (2020).

55. Häder, M. Delphi-Befragungen. (Westdeutscher Verlag, 2002).

56. Okoli, C. \& Pawlowski, S. D. The Delphi method as a research tool: An example, design considerations and applications. Inf. Manag. 42, 15-29 (2004).

57. Seuring, S. \& Müller, M. Core issues in sustainable supply chain management - A Delphi study. Bus. Strateg. Environ. 17, 455-466 (2008).

58. Greenhough, B. et al. Setting the agenda for social science research on the human microbiome. Palgrave Commun. 6, 1-11 (2020).

59. Sutherland, W. et al. The identification of 100 ecological questions of high policy relevance in the UK. J. Appl. Ecol. 43, 617-627 (2006).

60. Merli, R., Preziosi, M. \& Acampora, A. How do scholars approach the circular economy? A systematic literature review. J. Clean. Prod. 178, 703-722 (2018). 
61. Prieto-Sandoval, V., Jaca, C. \& Ormazabal, M. Towards a consensus on the circular economy. J. Clean. Prod. (2017). doi:10.1016/J.JCLEPRO.2017.12.224

62. Keller, R. Doing discourse research: an introduction for social scientists. (Sage, 2012).

63. Yanow, D. \& Schwarz-Shea, P. Interpretation and Method: Empirical Research Methods and the Interpretive Turn. (Routledge, 2015).

64. Sousa, D. Validation in Qualitative Research: General Aspects and Specificities of the Descriptive Phenomenological Method. Qual. Res. Psychol. 11, 211-227 (2014).

\section{Figures}

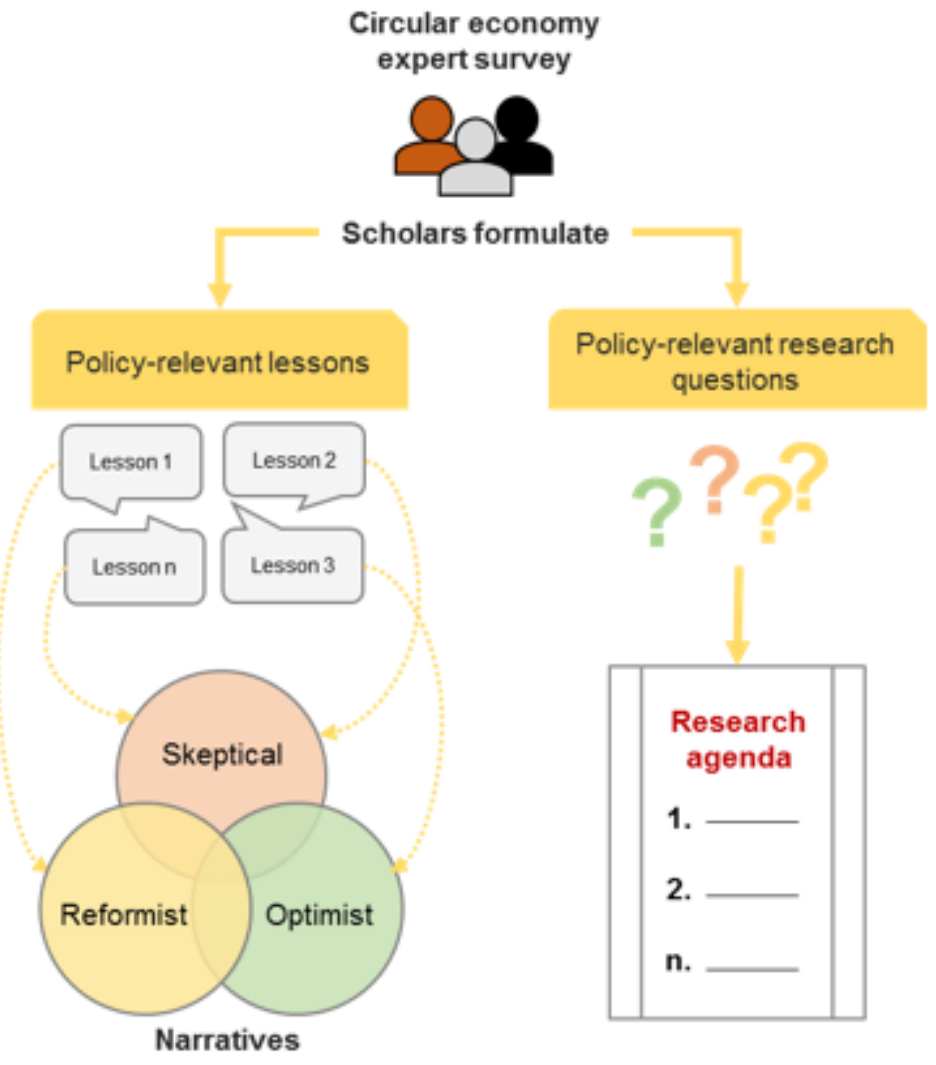

\section{Figure 1}

Simplified research design. Academic experts provided their main policy-relevant lessons and research questions on a sustainable circular economy. The lessons were grouped into three narratives (i.e. skeptical, reformist and optimist), whereas the questions were refined to elaborate a research agenda. 


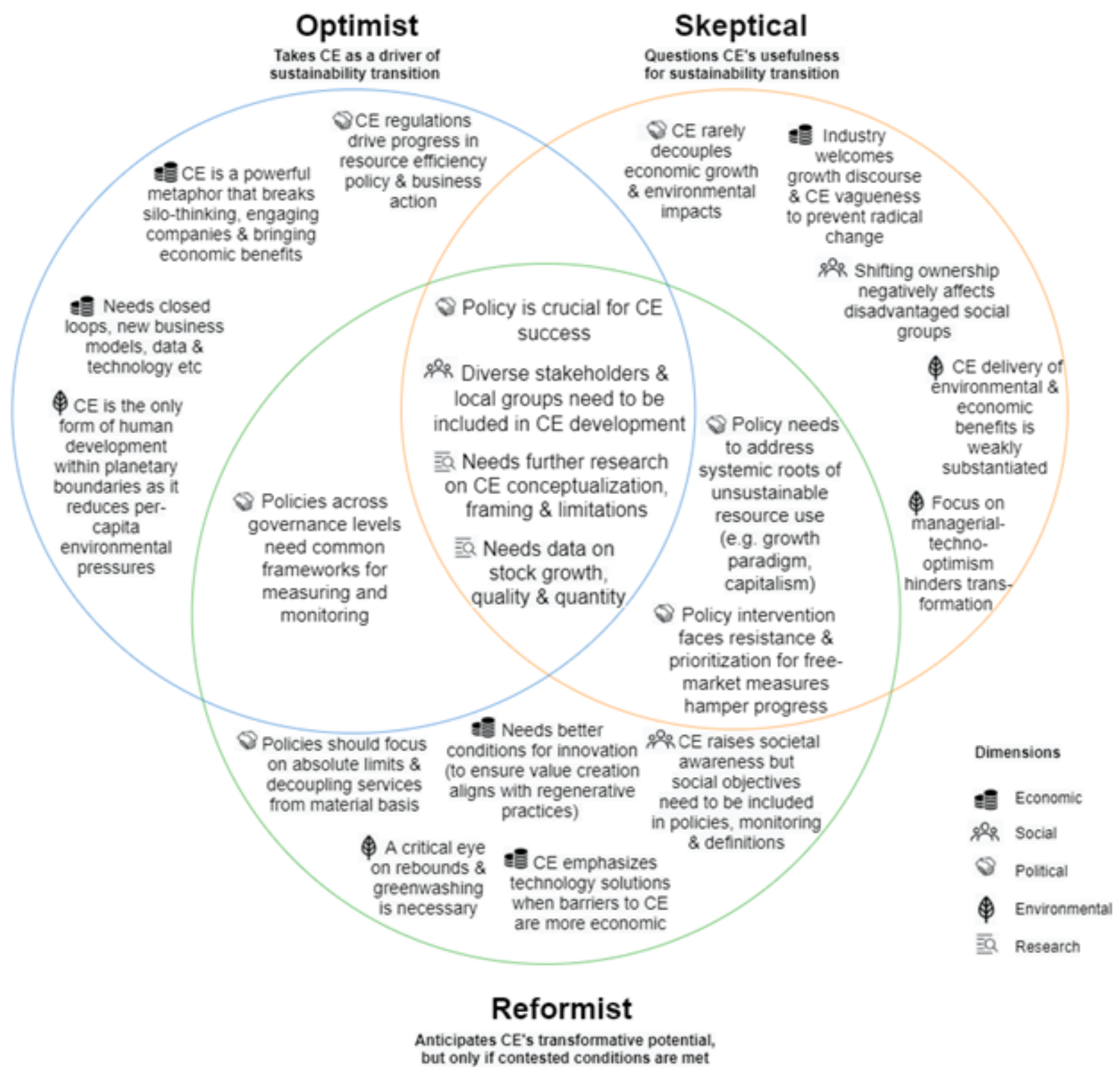

Figure 2

Narratives of policy-relevant lessons on a sustainable circular economy. Images: Flaticon.com. The diagram shows the ideal typical narratives drawn from policy-relevant lessons collected from the study's expert survey (see methods). Selected statements highlight the main lines of convergence and divergence of the three narratives. These results are a condensed version of the detailed lessons shown in Supporting Information 1. The narratives group lessons and not experts, who may draw on different narratives depending on the context. For better readability and overview, the lessons were grouped into dimensions - economic, social, political, environmental, and research.

\section{Supplementary Files}

This is a list of supplementary files associated with this preprint. Click to download. 
- SupportingInformation.pdf

Page 23/23 